\title{
Evaluating prevalence of depression, anxiety and hopelessness in patients with Vitiligo on an Iranian population
}

\author{
Nasrin Hamidizadeh $^{1 *}$ (D), Sara Ranjbar ${ }^{1}$, Ahmad Ghanizadeh ${ }^{2,3}$, Mohammad Mahdi Parvizi ${ }^{1}$, Peyman Jafari ${ }^{4}$ and \\ Farhad Handjani ${ }^{1}$
}

\begin{abstract}
Introduction: Vitiligo is caused by partial or complete destruction of melanocytes in the affected skin area and influences the patient's quality of life. Besides physical involvement, vitiligo patients experience a high level of stress. Depression and Anxiety are common psychiatric disorders in vitiligo patients.
\end{abstract}

Aim: This study, as the first study, evaluates hopelessness, anxiety, depression and general health of vitiligo patients in comparison with normal controls in an Iranian population.

Method: Hundred patients with vitiligo and hundred healthy controls were examined. General health, depression, hopelessness and anxiety were evaluated based on general health questionnaire. Anxiety, depression and hopelessness levels were analyzed using Chi-Square, and the mean value of general health was evaluated through t-test.

Results: The results showed that anxiety and hopelessness levels were significantly higher in vitiligo patients than those who are in healthy controls. This significant difference refers to high levels of anxiety and hopelessness among women with vitiligo.

It was also found that the single patients were more anxious, hopeless and depressive, while the married patients were only more anxious and hopeless than those who are in the control group, respectively.

General health of patients was significantly worse than in healthy controls. The low level of general health in patients was related to poorer level of general health among women with vitiligo.

Conclusion: It seems that women with vitiligo are more mentally stressed than men with vitiligo. Both singles and married vitiligo patients suffer from anxiety and hopelessness.

Keywords: Vitiligo, Depression, Anxiety, Hopelessness and general health

\section{Introduction}

Vitiligo is a chronic systemic disease which is characterized by hypopigmented macules and is caused by partial or complete destruction of melanocytes in the affected skin [1-3]. However, the exact cause of vitiligo is unknown; evidence suggests that various factors such as autoimmune,

\footnotetext{
* Correspondence: n.hamidizadeh.mdrc@gmail.com; nhamidizadeh@gmx.net In this article, we reported the hopelessness, anxiety, depression, and general health of vitiligo patients in comparison with controls, to emphasize the mental problems of patients more. We noticed that women with vitiligo are more anxious and hopeless than men with vitiligo. Both married and single patients suffer from anxiety and hopelessness.

${ }^{1}$ Molecular Dermatology Research Center, Shiraz University of Medical

Sciences, P.O. Box: 7134844119, Zand Avenue, Shiraz, Iran

Full list of author information is available at the end of the article
}

genetic and environmental factors are involved in the development of this disease. It affects $0.5-2 \%$ of the population worldwide regardless of race and gender $[4,5]$. Women and men are equally affected by the vitiligo [6]. Although it can initiate at any time $[7,8]$, the initiation in $50 \%$ of the people is before 20 years [9]. Depending on how soon it starts, more skin will be damaged. Low prevalence of vitiligo is observed in Scandinavian countries while Asian, especially Indians and Middle Eastern are at greater risk [10]. It should be noted that vitiligo is usually asymptomatic; it does not shorten the patient's life time and does not reduce physical activity [11, 12]. However, it results in several limitations such as regular visits for PUVA/narrow band UVB

(c) The Author(s). 2020 Open Access This article is distributed under the terms of the Creative Commons Attribution 4.0 International License (http://creativecommons.org/licenses/by/4.0/), which permits unrestricted use, distribution, and 
therapy, immunosuppressive therapies and risk of carcinogenesis with phototherapy.

Although vitiligo is not contagious, its effect on quality of life is related to psychological problems such as low self-esteem, embarrassment, negative effect on sexual relations, social isolation and experiencing vitiligo-related discrimination [13-15]. Therefore, it becomes a barrier for seeking job and marriage; and social stigma and suicidal ideation have been also reported [16].

Vitiligo patients experience a high level of stress and psychiatric disorders in addition to physical involvement. Depression, anxiety, suicidal thoughts, suicidal attempts, embarrassment, social problems, discomfort, cognitive impairment, embarrassment, and physical limitation were reported in vitiligo patients $[17,18]$. For this reason, vitiligo influences the patients' quality of life; so, related psychiatric disabilities should not be underestimated [19].

Furthermore, the prevalence of depression has increased in Europe, Asia, Africa, and the Middle East in the recent years [20].

The present study evaluated hopelessness, anxiety, depression and general health of vitiligo patients who were attended in the phototherapy center at Faghihi Hospital. Meanwhile, considering the fact that vitiligo causes and related psychological disorders vary in different societies; psychological problems of patients with vitiligo were investigated in Shiraz.

For this purpose, general health, depression, hopelessness and patients' anxiety were evaluated based on General Health Questionnaire-28 (GHQ-28) [21], Beck's Depression Inventory [22], Beck Hopelessness Scale [23] and Beck Anxiety Inventory [24], respectively.

\section{Method}

This study was conducted at Molecular Dermatology Research Center which is affiliated to Shiraz University of Medical Sciences and Dermatology Clinic of Faghihi Hospital in Shiraz during one and a half year.

Vitiligo patients, who referred dermatology clinic and were being treated with phototherapy, were randomly allocated to case and control group based on black permutation design.

All patients of both genders, who were at least 18 years old, without any serious mental and physical disability, and those who consented to participate were enrolled in this study [17]. The sample size was estimated based on the mean score (standard deviation) of Beck's depression inventory. The sample sizes was calculated according to previous studies between vitiligo patients [25] and healthy subjects (control group), respectively [26, 27]. Finally, 100 patients and 100 healthy controls were enrolled in the study.
Based on error rate of type I and according to formula: $N=4 \quad \sigma^{2}\left(z \frac{a}{2}+z \beta\right)^{2} /\left(\mu-\mu_{2}\right)^{2}, \alpha=0.05, \quad \beta=0.2$, power $(1-\beta)=80 \%, \mu_{1-} \mu_{2} / \sigma=1 / 2.5=0.4$.

Data were collected, using Beck's Depression Inventory (BDI), Beck Hopelessness Scale (BHS), Beck Anxiety Inventory (BAI), and General Health Questionnaire (GHQ 28) after consulting with a psychology professor.

Validity and reliability of these questionnaires were evaluated in the relevant studies [28-30]. Written informed consent was obtained from each participant and then, patient's information forms and the questionnaires were completed by each patient after the disease confirmation by a dermatologist.

Beck's Depression Inventory includes 21 questions, which evaluates the feelings of sadness, guilt, lack of interest, social isolation and suicidal ideation. Beck Hopelessness scale contains 20 statements, which measures negative attitudes or pessimism about the future, life prospect, achieving his/her desires or trusting the future.

Beck's Anxiety Inventory contains 21 questions which measures anxiety, difficulty relaxing, nervous tension, agitation and restlessness during the past week. General health was also measured through a General Health Questionnaire including 21 questions, which asks respondents to report how they felt during the last 4 weeks on a range of symptoms including somatic symptoms, anxiety, insomnia, social dysfunction and severe depression. Patient demographic characteristics such as age, age of onset, gender, hereditary disease, comorbidities, disease-related involvement of the body surface, type of treatment and marital status were added to the questionnaires.

Statistical analysis was done using SPSS statistical software, version 18 (IBM, Armonk, NY, USA). The levels of anxiety, depression and hopelessness were measured using Chi-Square; the mean value of general health was evaluated through $t$-test and correlation coefficient was calculated using Spearman's rank correlation coefficient. In all analytical tests, $p$ value more than 0.5 was considered significant.

\section{Results}

Generally, 100 vitiligo patients and 100 healthy controls (as the control group) participated in this study, among which 134 were female and 66 male. The mean age of the patients and control group was $34.50 \pm 12.225$ and $37.300 \pm 10.209$ years, respectively, which was not significantly different (Table 1).

The results showed that all three variables (hopelessness, anxiety and depression) had a positive and significant relationship with the disease duration. Age had negative relationship with hopelessness, anxiety and depression. It was significantly related to levels of hopelessness and 
Table 1 Shows demographic characteristics of vitiligo and control group

\begin{tabular}{|c|c|c|c|}
\hline & $n$ & Age (Mean $\pm S D)$ & $p$-value \\
\hline Case & 100 & $34.50 \pm 12.225$ & 0.081 \\
\hline Control & 100 & $37.30 \pm 10.209$ & \\
\hline \multicolumn{4}{|l|}{ Sex } \\
\hline \multicolumn{4}{|l|}{ Case } \\
\hline Female & 69 & $34.22 \pm 11.697$ & 0.732 \\
\hline Male & 31 & $35.13 \pm 13.515$ & \\
\hline \multicolumn{4}{|l|}{ Control } \\
\hline Female & 65 & $36.23 \pm 9.548$ & 0.160 \\
\hline Male & 35 & $39.26 \pm 11.200$ & \\
\hline \multicolumn{4}{|l|}{ Case } \\
\hline \multicolumn{4}{|c|}{ Age of onset of vitiligo } \\
\hline Female & 69 & $22.94 \pm 14.396$ & 0.373 \\
\hline Male & 31 & $25.61 \pm 12.339$ & \\
\hline \multicolumn{4}{|c|}{ Duration of disease } \\
\hline Female & 69 & $11.28 \pm 10.222$ & 0.425 \\
\hline Male & 31 & $9.52 \pm 10.013$ & \\
\hline \multicolumn{4}{|c|}{ Marital status (missing $=5$ ) } \\
\hline \multicolumn{4}{|l|}{ Married } \\
\hline Case & 56 & $39.02 \pm 11.298$ & 0.565 \\
\hline Control & 53 & $40.13 \pm 8.614$ & \\
\hline \multicolumn{4}{|l|}{ Single } \\
\hline Case & 42 & $28.10 \pm 10.164$ & 0.075 \\
\hline Control & 39 & $32.03 \pm 9.413$ & \\
\hline \multicolumn{4}{|l|}{ Widow } \\
\hline Case & 1 & 59 & 0.445 \\
\hline Control & 4 & $50.75 \pm 8.421$ & \\
\hline \multicolumn{4}{|c|}{ Family history of vitiligo } \\
\hline Female & 22 & $32.50 \pm 11.300$ & 0.445 \\
\hline Male & 7 & $36.71 \pm 16.070$ & \\
\hline
\end{tabular}

depression, but it had not significant relationship with the level of anxiety (Table 2).

The levels of hopelessness, anxiety and depression were also measured in both patient and healthy controls based on gender. The results also showed that the patients were significantly more anxious and hopeless compared to the healthy controls while there was no difference in the level of depression between the patients and healthy controls. On the other hand, the women with vitiligo were significantly more anxious and hopeless than men with vitiligo (Tables 3 and 4).

Married patients were more anxious and hopeless based on their levels of hopelessness, anxiety and depression in comparison with the healthy control. The results of this study also showed that depression, anxiety
Table 2 Shows the correlation between depression, anxiety and hopeless levels with age A: in case group and B: in control group, and C: shows correlation between depression, anxiety and hopeless levels with duration of disease in vitiligo group

\begin{tabular}{lcc}
\hline & Correlation Coefficient & $p$-value \\
\hline A: Case $(n=100)$ & & \\
Age & -0.255 & 0.010 \\
$\quad$ Depression & -0.147 & 0.150 \\
Anxiety & -0.243 & 0.015 \\
$\quad$ Hopeless & & \\
B: Control $(n=100)$ & & \\
Age & 0.051 & 0.619 \\
$\quad$ Depression & 0.026 & 0.801 \\
Anxiety & -0.011 & 0.911 \\
Hopeless & & \\
C: Case (n=100) & & 0.053 \\
Duration of illness & 0.194 & 0.003 \\
Depression & 0.293 & 0.031 \\
Anxiety & 0.216 & \\
Hopeless & &
\end{tabular}

and hopelessness levels of single patients were higher than the single subjects in the healthy controls. There was no significant difference in the levels of depression, anxiety and hopelessness between married and single vitiligo patients (Table 5 ).

Regarding to the vitiligo-related involvement of the body surface, women whose hands were affected, and married patients with facial, arm, and hand

Table 3 Show the prevalence and severity of depression, anxiety and hopelessness in the case and control group

\begin{tabular}{|c|c|c|c|}
\hline & Case & Control & $p$-value \\
\hline \multicolumn{4}{|c|}{ Severity of depression } \\
\hline Minimal & $53(53.0 \%)$ & $60(60 \%)$ & 0.157 \\
\hline Mild & 19 (19.0\%) & $25(25 \%)$ & \\
\hline Moderate & $16(16.0 \%)$ & $9(9 \%)$ & \\
\hline Severe & $12(12.0 \%)$ & $6(6 \%)$ & \\
\hline \multicolumn{4}{|c|}{ Severity of anxiety } \\
\hline Minimal & $32(32.7 \%)$ & $49(49.5 \%)$ & 0.015 \\
\hline Mild & $27(27.6 \%)$ & $30(30.3 \%)$ & \\
\hline Moderate & $25(25.5 \%)$ & $15(15.2 \%)$ & \\
\hline Severe & $14(14.3 \%)$ & $5(5.1 \%)$ & \\
\hline \multicolumn{4}{|c|}{ Severity of hopelessness } \\
\hline Minimal & $40(40.0 \%)$ & $48(48.5 \%)$ & 0.006 \\
\hline Mild & $34(34 \%)$ & $42(42.4 \%)$ & \\
\hline Moderate & $18(18.0 \%)$ & $9(9.1 \%)$ & \\
\hline Severe & $8(8.0 \%)$ & $0(0 \%)$ & \\
\hline
\end{tabular}


Table 4 Shows the prevalence and severity of depression, anxiety and hopelessness in women and men in the case and control group

\begin{tabular}{|c|c|c|c|c|c|c|}
\hline & \multicolumn{3}{|l|}{ Women } & \multicolumn{3}{|l|}{ Men } \\
\hline & Case & Control & $\overline{p \text {-value }}$ & Case & Control & $\overline{p \text {-value }}$ \\
\hline \multicolumn{7}{|c|}{ Severity of depression } \\
\hline Minimal & $36(52.2 \%)$ & $39(60.0 \%)$ & 0.203 & $17(54.8 \%)$ & $21(60.0 \%)$ & 0.698 \\
\hline Mild & $12(17.4 \%)$ & $16(24.6 \%)$ & & $7(22.6 \%)$ & $9(25.7 \%)$ & \\
\hline Moderate & $12(17.4 \%)$ & $5(7.7 \%)$ & & $4(12.9 \%)$ & $4(11.4 \%)$ & \\
\hline Severe & $9(13.0 \%)$ & $5(7.7 \%)$ & & $3(9.7 \%)$ & $1(2.9 \%)$ & \\
\hline \multicolumn{7}{|c|}{ Severity of anxiety } \\
\hline Minimal & 15 (22.4\%) & $34(53.1 \%)$ & 0.002 & $17(54.8 \%)$ & 15 (42.9\%) & 0.354 \\
\hline Mild & $21(31.3 \%)$ & $17(26.6 \%)$ & & $6(19.4 \%)$ & $13(37.1 \%)$ & \\
\hline Moderate & $21(31.3 \%)$ & $10(15.6 \%)$ & & $4(12.9 \%)$ & $5(14.3 \%)$ & \\
\hline Severe & $10(14.9 \%)$ & $3(4.7 \%)$ & & $4(12.9 \%)$ & $2(5.7 \%)$ & \\
\hline \multicolumn{7}{|c|}{ Severity of hopelessness } \\
\hline Minimal & $26(37.7 \%)$ & $36(56.3 \%)$ & 0.021 & $14(45.2 \%)$ & $12(34.3 \%)$ & 0.093 \\
\hline Mild & $24(34.8 \%)$ & $22(34.4 \%)$ & & $10(32.3 \%)$ & $20(57.1 \%)$ & \\
\hline Moderate & $14(20.3 \%)$ & $6(9.4 \%)$ & & $4(12.9 \%)$ & $3(8.6 \%)$ & \\
\hline Severe & $5(7.2 \%)$ & $0(0.0 \%)$ & & $3(9.7 \%)$ & $0(0.0 \%)$ & \\
\hline
\end{tabular}

involvement were significantly more anxious. Also, married patients whose genital areas were involved and single patients whose head/neck and trunk areas were involved were significantly more depressed (data was not shown).

Comparing the results of general health in patients with those of the control group showed that patients had significantly poorer general health than the healthy controls. Also, the results showed that women with vitiligo had poorer general health compared to women in the control group. However, the general health of men who suffer from vitiligo was not significantly different compared to the healthy men. There was no significant difference between women and men in relation to general health in patients and in controls, respectively (Table 6). Also, vitiligo involves body area which did not affect general health status (data not shown).

Table 5 Shows the prevalence and severity of depression, anxiety and hopelessness in married and single patients in the case and control group

\begin{tabular}{|c|c|c|c|c|c|c|}
\hline & \multicolumn{3}{|l|}{ Married } & \multicolumn{3}{|l|}{ Single } \\
\hline & Case & Control & $p$-value & Case & Control & $\overline{p \text {-value }}$ \\
\hline \multicolumn{7}{|c|}{ Severity of depression } \\
\hline Minimal & $35(62.5 \%)$ & $43(81.1 \%)$ & $0.137^{*}$ & $17(40.5 \%)$ & $14(35.9 \%)$ & $0.033^{*}$ \\
\hline Mild & $8(14.3 \%)$ & $2(3.8 \%)$ & & $10(23.8 \%)$ & $20(51.3 \%)$ & \\
\hline Moderate & $8(14.3 \%)$ & $5(9.4 \%)$ & & $8(19.0 \%)$ & $2(5.1 \%)$ & \\
\hline Severe & $5(8.9 \%)$ & $3(5.7 \%)$ & & $7(16.7 \%)$ & $3(7.7 \%)$ & \\
\hline \multicolumn{7}{|c|}{ Severity of anxiety } \\
\hline Minimal & 21 (38.9\%) & $33(62.3 \%)$ & $0.017^{*}$ & $10(23.8 \%)$ & $12(31.6 \%)$ & $0.008^{*}$ \\
\hline Mild & $15(27.8 \%)$ & $7(13.2 \%)$ & & $12(28.6 \%)$ & $21(55.3 \%)$ & \\
\hline Moderate & $9(16.7 \%)$ & $11(20.8 \%)$ & & $15(35.7 \%)$ & $3(7.9 \%)$ & \\
\hline Severe & $9(16.7 \%)$ & $2(3.8 \%)$ & & $5(11.9 \%)$ & $2(5.3 \%)$ & \\
\hline \multicolumn{7}{|c|}{ Severity of hopelessness } \\
\hline Minimal & $24(42.9 \%)$ & $34(65.4 \%)$ & $0.039^{*}$ & $15(35.7 \%)$ & $10(25.6 \%)$ & $0.040^{*}$ \\
\hline Mild & $18(32.1 \%)$ & $14(26.9 \%)$ & & 15 (35.7\%) & $24(61.5 \%)$ & \\
\hline Moderate & $11(19.6 \%)$ & $4(7.7 \%)$ & & $7(16.7 \%)$ & $5(12.8 \%)$ & \\
\hline Severe & $3(5.4 \%)$ & $0(0.0 \%)$ & & $5(11.9 \%)$ & $0(0.0 \%)$ & \\
\hline
\end{tabular}


Table 6 shows GHQ positive and GHQ negative in the vitiligo group in comparison with the controls

\begin{tabular}{|c|c|c|c|c|c|c|}
\hline & $\mathrm{n}$ & $\mathrm{GHQ}^{\mathrm{a}}($ Mean $\pm \mathrm{SD})$ & $p$-value & $\mathrm{GHQ}-^{\mathrm{b}} \mathrm{n}(\%)$ & $\mathrm{GHQ}+{ }^{\mathrm{c}} \mathrm{n}(\%)$ & $p$-value \\
\hline Case & 99 & $26.46 \pm 15.183$ & 0.036 & $50(50.5)$ & $49(49.5)$ & 0.018 \\
\hline Control & 100 & $22.12 \pm 13.852$ & & $67(67.0)$ & $33(33.0)$ & \\
\hline \multicolumn{7}{|l|}{ Case } \\
\hline Women & 68 & $27.74 \pm 15.554$ & 0.219 & $33(48.5)$ & $35(51.5)$ & 0.666 \\
\hline Men & 31 & $23.68 \pm 14.181$ & & $17(54.8)$ & $14(45.2)$ & \\
\hline \multicolumn{7}{|l|}{ Control } \\
\hline Woman & 65 & $20.35 \pm 13.008$ & 0.082 & $45(69.2)$ & $20(30.8)$ & 0.656 \\
\hline Men & 35 & $25.40 \pm 14.939$ & & $22(62.9)$ & $13(37.1)$ & \\
\hline \multicolumn{7}{|l|}{ Women } \\
\hline Case & 68 & $27.74 \pm 15.554$ & 0.004 & $33(42.3)$ & 35 (63.6) & 0.022 \\
\hline Control & 65 & $20.35 \pm 13.008$ & & $45(57.7)$ & $20(36.4)$ & \\
\hline \multicolumn{7}{|l|}{ Men } \\
\hline Case & 31 & $23.68 \pm 14.181$ & 0.634 & $17(43.6)$ & $14(51.9)$ & 0.618 \\
\hline Control & 35 & $25.40 \pm 14.939$ & & $22(56.4)$ & $13(48.1)$ & \\
\hline
\end{tabular}

${ }^{\mathrm{a} G e n e r a l ~ H e a l t h ~ Q u e s t i o n n a i r e ~(G H Q) ~}$

bhaving normal mental health

chaving poor mental health

\section{Discussion}

Vitiligo is an acquired disease, which is caused by the loss of functioning melanocytes, and its cause is still unknown. There are different treatment options based on different mechanisms to treat vitiligo.

Although vitiligo does not cause physical disability, long-term treatment, lack of consistent effective therapy and a significant financial burden are stressful for patients who have been involved. This issue affects the patients' emotions, mental well-being and sexual relationship, and has a significant effect on patients' quality of life. In reviewing DLQI studies, patients' quality of life with vitiligo has been evaluated over the past 20 years [31]. In several studies, poor quality of life of patients was observed in some countries [32] as well as in Iran [33-35]. Studies showed poorer quality of life in women with vitiligo compared to men with vitiligo [36], in married women in comparison with single women [33], and in Muslim women in comparison with Muslim men [37]. Nonetheless, depression $[20,25,38,39]$, anxiety and hopelessness [40, 41], were more reported in vitiligo patients.

In this study we investigated the hopelessness, depression, anxiety and general health levels of vitiligo patients. We found that the levels of anxiety and hopelessness in patients were significantly higher than healthy controls.

The results also showed that women with vitiligo compered to healthy controls were more anxious and hopeless while, there was no significant difference in the levels of anxiety and hopelessness among men with vitiligo in comparison with the healthy controls.

It seems that the significant difference in the levels of hopelessness and anxiety between the patients and controls was due to low significant levels of these two variables between women. Our results were consistent with the results of previous studies, which suggest women with vitiligo had poorer quality of life [33, 36, 37, 42]. However, other studies concluded that vitiligo patients suffer more from depression and anxiety [20,38-41]. On the contrary to other studies, this study showed that the women were more anxious and hopeless. The married patients with genital areas and feet involvement and the single patients with trunk involvement were significantly more depressed.

The results also showed that there was a significant difference in general health between the patients, so that the patients had a worse general health. The significant difference in the general health between the patients and the healthy controls is due to a poorer general health of women with vitiligo. The results of this study also showed that married people and singles were more hopeless and anxious than their corresponding controls, whereby the singles were also even more depressed.

Some studies showed that the quality of life of vitiligo patients was affected by stigma [43], sexual dissatisfaction [44] and lack of self-esteem [45], and patients have difficulty to find a job and consider vitiligo as a significant obstacle to get married [16]. Therefore, control or treatment of vitiligo patients requires general identification of the patient's problems, both psychological and physical, and individual therapy. In this sense, dermatologists should evaluate the psychiatric status of women with vitiligo in addition to physical treatment. Furthermore, the interaction between the patient and the doctor is also significant. Previous studies showed the effects of psychiatric disorders, patient-physician interaction, and 
also evaluation of patients' mental and physical health on their quality of life $[17,46,47]$. Papadopoulos et al. showed that counseling can help to improve self-esteem and quality of life in vitiligo patients and may even have a positive effect on the course of the disease [48]. Other studies have confirmed that it is important to identify and treat patients' psychosocial and social factors for more positive effect on quality of life and treatment $[49,50]$.

\section{Conclusion}

Women suffer from vitiligo more than men and are more anxious and hopeless. The physician should consider both the physical and psychological problems especially in women in order to obtain the best possible treatment.

\section{Abbreviations}

BAl: Beck Anxiety Inventory; BDI: Beck's Depression Inventory; BHS: Beck Hopelessness Scale; DLQI: Dermatology Life Quality Index; GHQ: Genera Health Questionnaire; IBM: International Business Machines; NY: New York; SD: Standard deviation; USA: United States of America

\section{Acknowledgements}

We would like to thank Dr. Armaghan Ashraf for her support and all the patients who participated in this project.

\section{Authors' contributions}

$\mathrm{NH}$ : Conceptualization \& project administration. SR Collected the data. AG: Methodology. MMP, PJ, NH: Analysis and interpretation of the data. NH, SR: Supervision. NH, AG, FH Writing - original draft. NH: Writing - review \& editing. All authors read and approved the final manuscript.

\section{Funding}

This project was financially supported by a grant (Grand number: 92-01-656410) from Molecular Dermatology Research Center, Shiraz University of Medical Sciences, Shiraz, Iran.

\section{Availability of data and materials}

The data is presented and kept by the authors and is available for scrutiny.

\section{Ethics approval and consent to participate}

This study was approved by the local Ethics Committee of Shiraz University of Medical Science (EC-SUMS Number: 93-6410), Informed consent was obtained from each participants.

\section{Consent for publication}

All authors understand that the manuscript will be freely available on the internet and may be seen by the general public

\section{Competing interests}

The authors declare that they have no competing interests.

\section{Author details}

'Molecular Dermatology Research Center, Shiraz University of Medical Sciences, P.O. Box: 7134844119, Zand Avenue, Shiraz, Iran. ${ }^{2}$ Research Center for Psychiatry and Behavioral Sciences, Department of Psychiatry, Shiraz University of Medical Sciences, Shiraz, Iran. ${ }^{3}$ Department of Psychiatry, UCLA-Kern Psychiatry Residency Program, Kern Medical, Kern Behavioral Health and Recovery Services, Bakersfield, CA, USA. ${ }^{4}$ Department of Biostatistics, Shiraz University of Medical Sciences, Shiraz, Iran.
Received: 27 November 2019 Accepted: 22 January 2020

Published online: 03 February 2020

\section{References}

1. Tarle RG, Nascimento LM, Mira MT, Castro CC. Vitiligo--part 1. An Bras Dermatol. 2014;89(3):461-70 Epub 2014/06/18. PubMed PMID: 24937821; PubMed Central PMCID: PMC4056705.

2. Tobin DJ, Swanson NN, Pittelkow MR, Peters EM, Schallreuter KU. Melanocytes are not absent in lesional skin of long duration vitiligo. J Pathol. 2000;191(4):407-16. https://doi.org/10.1002/1096-9896(2000)9999: 9999<:"AID-PATH659>3.0.CO:2-D Epub 2000/08/05 PubMed PMID: 10918216.

3. Le Poole IC, van den Wijngaard RM, Westerhof W, Dutrieux RP, Das PK. Presence or absence of melanocytes in vitiligo lesions: an immunohistochemical investigation. J Invest Dermatol. 1993;100(6):816-22 Epub 1993/06/01. PubMed PMID: 7684427.

4. Laddha NC, Dwivedi M, Mansuri MS, Gani AR, Ansarullah M, Ramachandran $A V$, et al. Vitiligo: interplay between oxidative stress and immune system. Exp Dermatol. 2013;22(4):245-50. https://doi.org/10.1111/exd.12103 Epub 2013/02/22. PubMed PMID: 23425123

5. Silverberg NB. The epidemiology of vitiligo. Curr Derm Rep. 2015:4:36-43.

6. Mosher DB, Fitzpatrick TB, Ortonne JP, Hori Y. Disorders of pigmentation. In: Fitzpatrick TB, Eisen AZ, Wolff K, Freedberg IM, Austen KF, editors. Dermatology in general medicine. New York: McGraw-Hill Book Co.; 1987. p. 794-876.

7. Masini C, AD Vitiligo. 4th ed. In: Williams H. Birgby M, Diepgen T. Herxheimer A. Naldi L. Rzany B. editors. Evidence-based dermatology. BMJ Publishing Group. 2003.

8. Majumder PP, Nordlund JJ, Nath SK. Pattern of familial aggregation of vitiligo. Arch Dermatol. 1993;129(8):994-8 Epub 1993/08/01. PubMed PMID: 8352624.

9. Whitton ME, Ashcroft DM, Barrett CW, Gonzalez U. Interventions for vitiligo. Cochrane Database Syst Rev. 2006;1:CD003263. https://doi.org/10.1002/ 14651858.CD003263.pub3 PubMed PMID: 16437451.

10. Hahn SK, Nordlund JJ. Vitiligo. Oxford: Blackwell Science; 2000. p. 1-306.

11. Braun-Falco O, Plewig G, Wolf HH. Dermatologie und Venerologie, 4. Aufl., Depigmentierungen. Berlin, Heidelberg, New York: Springer; 1996. p. $931 \mathrm{ff}$

12. De Gruyter W. Pschyrembel Klinisches Wörterbuch (259., neu bearbeitete Auflage). Berlin: Walter de Gruyter Gmbh \& Co. KG; 2002.

13. Porter J, Beuf AH, Nordlund JJ, Lerner AB. Psychological reaction to chronic skin disorders: a study of patients with vitiligo. Gen Hosp Psychiatry. 1979; 1(1):73-7 Epub 1979/04/01. PubMed PMID: 499777.

14. Porter J, Beuf AH, Lerner A, Nordlund J. Response to cosmetic disfigurement: patients with vitiligo. Cutis. 1987;39(6):493-4 Epub 1987/06/ 01. PubMed PMID: 3608575.

15. Porter JR, Beuf $A H$, Lerner $A B$, Nordlund JJ. The effect of vitiligo on sexual relationships. J Am Acad Dermatol. 1990;22(2 Pt 1):221-2 Epub 1990/02/01. PubMed PMID: 2312803

16. Pahwa P, Mehta M, Khaitan BK, Sharma VK, Ramam M. The psychosocial impact of vitiligo in Indian patients. Ind J Derm Venereol Leprology. 2013; 79(5):679-85. https://doi.org/10.4103/0378-6323.116737 Epub 2013/08/27. PubMed PMID: 23974584.

17. Ongenae K, Beelaert L, van Geel N, Naeyaert JM. Psychosocial effects of vitiligo. Journal of the European Academy of Dermatology and Venereology : JEADV. 2006;20(1):1-8. https://doi.org/10.1111/j.1468-3083.2005.01369.x Epub 2006/01/13. PubMed PMID: 16405601.

18. Sarkar S, Sarkar T, Sarkar A, Das S. Vitiligo and Psychiatric Morbidity: A Profile from a Vitiligo Clinic of a Rural-based Tertiary Care Center of Eastern India. Ind J Dermatol. 2018;63(4):281-4. https://www.ncbi.nlm.nih.gov/pmc/ articles/PMC6052755/.

19. Shenefelt PD. Psychological interventions in the management of common skin conditions. Psychol Res Behav Manag. 2010:3:51-63 Epub 2010/01/01. PubMed PMID: 22110329; PubMed Central PMCID: PMC3218765.

20. Lai YC, Yew YW, Kennedy C, Schwartz RA. Vitiligo and depression: a systematic review and meta-analysis of observational studies. $\mathrm{Br} J$ Dermatol. 2017;177(3):708-18. https://doi.org/10.1111/bjd.15199 Epub 2016/11/24. PubMed PMID: 27878819

21. Goldberg DP, Hillier VF. A scaled version of the general health questionnaire. Psychol Med. 1979:9(1):139-45 PubMed PMID: 424481.

22. Beck AT, Ward CH, Mendelson M, Mock J, Erbaugh J. An inventory for measuring depression. Arch Gen Psychiatry. 1961:4:561-71 PubMed PMID: 13688369 . 
23. Beck AT, Weissman A, Lester $D$, Trexler $L$. The measurement of pessimism: the hopelessness scale. J Consult Clin Psychol. 1974;42(6):861-5 PubMed PMID: 4436473.

24. Beck AT, Epstein N, Brown G, Steer RA. An inventory for measuring clinical anxiety: psychometric properties. J Consult Clin Psychol. 1988;56(6):893-7 PubMed PMID: 3204199.

25. Mattoo SK, Handa S, Kaur I, Gupta N, Malhotra R. Psychiatric morbidity in vitiligo and psoriasis: a comparative study from India. J Dermatol. 2001;28(8): 424-32 PubMed PMID: 11560159.

26. Mattoo SK, Handa S, Kaur I, Gupta N, Malhotra R. Psychiatric morbidity in vitiligo: prevalence and correlates in India. J Eur Acad Dermatol Venereol. 2002;16(6):573-8 PubMed PMID: 12482039.

27. Kruger C, Smythe JW, Spencer JD, Hasse S, Panske A, Chiuchiarelli G, et al. Significant immediate and long-term improvement in quality of life and disease coping in patients with vitiligo after group climatotherapy at the Dead Sea. Acta Derm Venereol. 2011;91(2):152-9. https://doi.org/10.2340/ 00015555-1037 PubMed PMID: 21240455.

28. Taghavi SMR. Validity and reliability of the general health questionnaire (GHQ28) in college students of Shiraz University. J Psycho. 2002;4(20):381-98.

29. Goudarzi MA. The study of reliability and validity of Beck hopelessness scale in a group of Shiraz University students. J Soc Sci Hum Shiraz Univ. 2002;18. 2(36):27-39.

30. Kaviani H, Seyfourian H, Sharifi V, Ebrahimkhani N. Reliability and validity of Anxiety and Depression Hospital Scales (HADS): Iranian patients with anxiety and depression disorders. Tehran Univ Med J. 2009;67(5):379-85.

31. Amer AA, Gao XH. Quality of life in patients with vitiligo: an analysis of the dermatology life quality index outcome over the past two decades. Int J Dermatol. 2016;55(6):608-14.

32. Cupertino F, Niemeyer-Corbellini JP, Ramos ESM. Psychosomatic aspects of vitiligo. Clin Dermatol. 2017;35(3):292-7. https://doi.org/10.1016/j. clindermatol.2017.01.001 Epub 2017/05/18. PubMed PMID: 28511827.

33. Dolatshahi M, Ghazi P, Feizy $V$, Hemami MR. Life quality assessment among patients with vitiligo: comparison of married and single patients in Iran. Indian J Dermatol Venereol Leprol. 2008;74(6):700 Epub 2009/01/31. PubMed PMID: 19177700.

34. Aghaei S, Sodaifi M, Jafari P, Mazharinia N, Finlay AY. DLQI scores in vitiligo: reliability and validity of the Persian version. BMC Dermatol. 2004;4:8. https://doi.org/10.1186/1471-5945-4-8 Epub 2004/08/06. PubMed PMID: 15294022; PubMed Central PMCID: PMC514558.

35. Mashayekhi $\mathrm{V}$, Javidi Z, Kiafar B, Manteghi AA, Saadatian V, Esmaeili HA, et al. Quality of life in patients with vitiligo: a descriptive study on 83 patients attending a PUVA therapy unit in Imam Reza Hospital, Mashad. Indian J Dermatol Venereol Leprol. 2010;76(5):592. https://doi.org/10.4103/0378-6323. 69097 Epub 2010/09/10. PubMed PMID: 20827019.

36. Hedayat K, Karbakhsh M, Ghiasi M, Goodarzi A, Fakour Y, Akbari Z, et al. Quality of life in patients with vitiligo: a cross-sectional study based on Vitiligo quality of life index (VitiQoL). Health Qual Life Outcomes. 2016;14:86. https://doi.org/10.1186/s12955-016-0490-y Epub 2016/06/09. PubMed PMID: 27267598; PubMed Central PMCID: PMC4897932.

37. Borimnejad L, Parsa Yekta Z, Nikbakht-Nasrabadi A, Firooz A. Quality of life with vitiligo: comparison of male and female muslim patients in Iran. Gender Med. 2006;3(2):124-30 Epub 2006/07/25. PubMed PMID: 16860271.

38. Al-Harbi M. Prevalence of depression in vitiligo patients. Skinmed. 2013; 11(6):327-30 Epub 2014/02/13. PubMed PMID: 24517036.

39. Wang G, Qiu D, Yang H, Liu W. The prevalence and odds of depression in patients with vitiligo: a meta-analysis. J Eur Acad Dermatol Venereol. 2017. https://doi.org/10.1111/jdv.14739 Epub 2017/12/10. PubMed PMID: 29222958.

40. Ahmed I, Ahmed S, Nasreen S. Frequency and pattern of psychiatric disorders in patients with vitiligo. J Ayub Med Coll Abbottabad. 2007;19(3): 19-21 Epub 2008/05/01. PubMed PMID: 18444584

41. Bilgic O, Bilgic A, Akis HK, Eskioglu F, Kilic EZ. Depression, anxiety and health-related quality of life in children and adolescents with vitiligo. Clin Exp Dermatol. 2011;36(4):360-5. https://doi.org/10.1111/j.1365-2230.2010. 03965.x Epub 2011/01/05. PubMed PMID: 21198786.

42. Ongenae K, Van Geel N, De Schepper S, Naeyaert JM. Effect of vitiligo on selfreported health-related quality of life. Br J Dermatol. 2005;152(6):1165-72.

43. Catucci Boza J, Giongo N, Machado P, Horn R, Fabbrin A, Cestari T. Quality of life impairment in children and adults with Vitiligo: a cross-sectional study based on dermatology-specific and disease-specific quality of life instruments. Dermatology. 2016;232(5):619-25.
44. Sarhan D, Mohammed GF, Gomaa AH, Eyada MM. Female genital dialogues: female genital self-image, sexual dysfunction, and quality of life in patients with Vitiligo with and without genital affection. J Sex Marital Therapy. 2016; 42(3):267-76.

45. Elbuluk N, Ezzedine K. Quality of life, burden of disease, co-morbidities, and systemic effects in Vitiligo patients. Dermatol Clin. 2017;35(2):117-28. https://doi.org/10.1016/j.det.2016.11.002 Epub 2017/03/21. PubMed PMID: 28317521.

46. Sampogna F, Raskovic D, Guerra L, Pedicelli C, Tabolli S, Leoni L, et al. Identification of categories at risk for high quality of life impairment in patients with vitiligo. Br J Dermatol. 2008;159(2):351-9. https://doi.org/10. 1111/j.1365-2133.2008.08678.x Epub 2008/06/21. PubMed PMID: 18565189.

47. Silvan M. The psychological aspects of vitiligo. Cutis. 2004;73(3):163-7 Epub 2004/04/13. PubMed PMID: 15074343.

48. Papadopoulos L, Bor R, Legg C. Coping with the disfiguring effects of vitiligo: a preliminary investigation into the effects of cognitive-behavioural therapy. Brit J Med Psychol. 1999;72(Pt 3):385-96 Epub 1999/10/19. PubMed PMID: 10524722

49. Gupta MA, Gupta AK. Psychiatric and psychological co-morbidity in patients with dermatologic disorders: epidemiology and management. Am J Clin Dermatol. 2003;4(12):833-42.

50. Parsad D, Pandhi R, Dogra S, Kanwar AJ, Kumar B. Dermatology life quality index score in vitiligo and its impact on the treatment outcome. $\mathrm{Br} J$ Dermatol. 2003;148(2):373-4 Epub 2003/02/18. PubMed PMID: 12588405.

\section{Publisher's Note}

Springer Nature remains neutral with regard to jurisdictional claims in published maps and institutional affiliations.
Ready to submit your research? Choose BMC and benefit from:
- fast, convenient online submission
- thorough peer review by experienced researchers in your field
- rapid publication on acceptance
- support for research data, including large and complex data types
- gold Open Access which fosters wider collaboration and increased citations
- maximum visibility for your research: over $100 \mathrm{M}$ website views per year
At BMC, research is always in progress.
Learn more biomedcentral.com/submissions 